\title{
Purification and biochemical characterization of the ATP synthase from Heliobacterium modesticaldum
}

Jay-How Yang ${ }^{1,2}$, Iosifina Sarrou ${ }^{1,4}$, Jose M. Martin-Garcia ${ }^{1,2}$, Shangji Zhang ${ }^{3}$, Kevin E. Redding $^{1}$, and Petra Fromme ${ }^{1,2 *}$

${ }^{1}$ Department of Chemistry and Biochemistry, Arizona State University, Tempe, AZ 85287-1604 USA.

${ }^{2}$ Center for Applied Structural Discovery, The Biodesign Institute, Arizona State University, Tempe, AZ 85287-1604, USA

${ }^{3}$ School of Life Sciences, Arizona State University, Tempe, AZ 85287-1604, USA

${ }^{4}$ Institute of Molecular Biology \& Biotechnology, Foundation for Research \&

Technology-Hellas, Nikolaou Plastira 100 GR-70013, Heraklion, Crete, GREECE.

Keywords: ATP synthase; Heliobacterium modesticaldum; ATP hydrolysis; in-gel function assay

* Corresponding author: pfromme@asu.edu, phone +1 480965 9028, fax +1 480965 2747 


\begin{abstract}
Heliobacterium modesticaldum is an anaerobic photosynthetic bacterium that grows optimally at $\mathrm{pH} 6-7$ and $52^{\circ} \mathrm{C}$ and is the only phototrophic member of the Firmicutes phylum family (gram-positive bacteria with low GC content). The ATP synthase of $H$. modesticaldum was isolated and characterized at the biochemical and biophysical levels. The isolated holoenzyme exhibited the subunit patterns of F-type ATP synthases containing a 5-subunit hydrophilic $\mathrm{F}_{1}$ subcomplex and a 3-subunit hydrophobic $\mathrm{F}_{\mathrm{O}}$ subcomplex. ATP hydrolysis by the isolated $\mathrm{HF}_{1} \mathrm{~F}_{\mathrm{O}}$ ATP synthase was successfully detected after pretreatment with different detergents by an in-gel ATPase activity assay, which showed that the highest activity was detected in the presence of mild detergents such as LDAO; moreover, high catalytic activity in the gel was already detected after the initial incubation period of $0.5 \mathrm{~h}$. In contrast, $\mathrm{HF}_{1} \mathrm{~F}_{\mathrm{O}}$ showed extremely low ATPase activity in harsher detergents such as TODC. The isolated fully functional enzyme will form the basis for future structural studies.
\end{abstract}




\section{Introduction}

Heliobacterium modesticaldum is a thermophilic anoxygenic phototrophic bacterium that grows either photoheterotrophically or chemotrophically in the dark by fermentation but does not grow photoautotrophically due to the lack of several genes encoding key enzymes required for the known autotrophic carbon fixation pathways $[1,2]$. Heliobacterium modesticaldum may have played a key role in the evolution of phototrophic bacteria. The electron transport chain contains a type I photosynthetic reaction center (RC) that employs bacteriochlorophyll (Bchl $g$ ) as the primary electron donor. The majority of recent studies have focused on characterization of the photosynthetic reaction center and electron transport chain. The energy metabolism of $H$. modesticaldum has been studied to a much lesser extend, and no isolation or biochemical studies have been reported thus far for the H. modesticaldum ATP synthase, which is one of the key enzymes involved in bioenergetic energy conversion. Based on the genomic information of $H$. modesticaldum, it is known that this organism contains a gene cluster for an F-type ATP synthase in which all eight subunits are encoded in a single conserved operon [2]. However, due to the lack of any biochemical data, the structure, function and regulation of the ATP synthase of $H$. modesticaldum are still poorly understood.

The membrane-bound F-type ATP synthase is a multi-subunit membrane protein complex that functions as a universal rotary nano-machine in the energy-transducing membranes of bacteria, mitochondria, and chloroplasts [3]. The chloroplast ATP synthase is a multi-subunit complex comprising 9 different subunits $\left(\alpha_{3} \beta_{3} \gamma \delta \varepsilon \mathrm{I}_{1} \mathrm{II}_{1} \mathrm{III}_{12-14} \mathrm{IV}_{1}\right)$ located in two major domains $\left(\mathrm{CF}_{1}\right.$ and $\left.\mathrm{CF}_{0}\right)$. The hydrophilic $\mathrm{CF}_{1}$ domain comprises 5 different subunits $\left(\alpha_{3} \beta_{3} \gamma \delta \varepsilon\right)$. In most bacteria, the hydrophobic membrane-bound $\mathrm{CF}_{0}$ domain comprises 3 different subunits $\left(\mathrm{a}, \mathrm{b}_{2}\right.$, and $\mathrm{c}_{10-15}$ ), which correspond to the chloroplast subunits $\left(\mathrm{a}=\mathrm{IV}_{1}, \mathrm{~b}_{2}=\mathrm{I}_{1}\right.$ and $\mathrm{II}_{1}$, and $\mathrm{c}_{10-15}=$ $\mathrm{III}_{10-15} \mathrm{IV}_{1}$ ). The $\mathrm{CF}_{1}$ and $\mathrm{CF}_{0}$ domains are connected in the $\mathrm{CF}_{1} \mathrm{~F}_{0}$ protein complex by two peripheral stalks: a central interior stalk comprising $\gamma$ and $\varepsilon$ subunits, and the peripheral exterior stalk comprising the I and II subunits as well as the $\delta$ subunit [4]. Three ATP molecules are synthesized in the three catalytic sites in $\mathrm{CF}_{1}$ during one full rotation of the central stalk and the c-ring, driven by an electrochemical proton gradient. Up to 400 ATP molecules per second are synthesized in the natural environment [5-8]. F-type ATP synthases can act in both synthesis and hydrolysis directions; in the synthesis direction, the enzyme synthesizes ATP, which is driven by an electrochemical proton gradient. In the reverse direction, ATP hydrolysis drives the translocation of protons across the photosynthetic membrane. 
However, photosynthetic organisms must avoid ATP hydrolysis in the absence of an electrochemical gradient; therefore, the hydrolytic function of $\mathrm{CF}_{1} \mathrm{~F}_{\mathrm{O}}$ is inactivated at night by redox modulation of a disulfide bridge on its $\gamma$ subunit via thioredoxin [9-15].

This study is, to the best of our knowledge, the first report of the successful isolation and biochemical characterization of the ATP synthase from Heliobacterium modesticaldum. We used an in-gel ATPase activity assay, which is well established and has previously been successfully applied to the detection of the activity of mitochondrial ATP synthases and spinach chloroplast ATP synthases, as well as the ATP synthases from the cyanobacterium $T$. elongatus and the green algae $C$. reinhardtii [16], to study the activity of the ATP synthase in the presence of different detergents. In contrast to mitochondrial ATP synthases, for which high ATP hydrolysis activities have been reported [16], the chloroplast ATP synthase has low ATPase activity due to the inhibition mechanism that prevents wasteful ATP hydrolysis in the dark. This inactivation is mediated by a conformational change of the $\varepsilon$ subunit of $\mathrm{CF}_{1}$ $[17,18]$, which occurs induced by the lack of proton gradient, the binding of $\mathrm{Mg}^{2+}$-ATP [19-22], and the oxidation of cysteine residues in the $\gamma$ subunits to a disulfide bond [23, 24]. Several studies used harsh pre-treatments of the chloroplast enzyme, including heating, organic solvents, and trypsin, to stimulate the ATPase activity of $\mathrm{CF} 1$, which is the hydrophilic part of the enzyme that contains the nucleotide binding sites [25-28]. The interaction of some harsher detergents with the solubilized $\mathrm{CF}_{1}$ part of the chloroplast ATP synthases led to enhanced ATPase activity $[16,29,30]$. The stimulation of $\mathrm{CF}_{1}$ ATPase activity by harsh detergents that form small micelles may be induced by the dissociation of the $\varepsilon$ subunit from the chloroplast $\mathrm{CF}_{1}$ subcomplex. Various detergents, including alkylglucosides, LDAO, and TDOC, have previously been tested to study the effect of the dissociation of the $\mathrm{CF}_{1}-\varepsilon$ subunit $[16,29,30]$. With an increase of the micelle size by increasing the chain length, the interaction of alkylglucosides with $\mathrm{CF}_{1}$ becomes less and less effective in removing the $\varepsilon$ subunit, resulting in lower ATPase activity [30].

In contrast to the chloroplast enzyme, the hydrolytic function of ATP synthase is a vitally important process in anaerobic bacteria that lack a membrane-bound respiratory chain to establish a gradient of electrochemical potential for protons or sodium ions [31]. The $\mathrm{F}_{1} \mathrm{~F}_{\mathrm{O}}$ ATP synthase of the alkaliphilic bacterium Natranaerobius thermophilus is one example that it does not function in ATP synthesis [31] but the enzyme catalyzes ATP hydrolysis to expel cytoplasmic $\mathrm{Na}^{+}$to avoid $\mathrm{Na}$ toxicity. $H$. modesticaldum lacks the internal membranes present in 
cyanobacteria; the photosynthetic electron transport chain is instead embedded into the cytoplasmic membrane. Therefore, it is commonly assumed that an electrochemical gradient across the cytoplasmic membrane that is established during the photosynthetic process, drives ATP synthesis. However, whether ATP hydrolysis might also be an essential function of the heliobacterial $\mathrm{HF}_{1} \mathrm{~F}_{\mathrm{O}}$ remains unknown. It is also unknown whether regulation of the reverse direction of the $H$. modesticaldum ATP synthase is similar to the inactivation mechanism of $\mathrm{CF}_{1} \mathrm{~F}_{\mathrm{O}}$ at night.

In this manuscript, we report on the isolation and biochemical characterization of the functional ATP synthase from $H$. modesticaldum. The identities of all subcomplexes and individual subunits of the ATP synthase were determined. We also discovered that the isolated ATP synthase remains active during native gel electrophoresis using an in-gel ATPase activity assay. In contrast to the chloroplast ATP-synthase, no activation is required for the ATPase activity of the ATP synthase from H. modesticaldum. The H. modesticaldum enzyme is fully active in the presence of mild detergents, while it is denatured in harsh detergents. Our studies show that the isolated ATP synthase from $H$. modesticaldum is fully functional and is suitable for further functional and structural studies. 


\section{Materials and methods}

\section{Purification of the ATP synthase complex from Heliobacterium modesticaldum}

The $\mathrm{HF}_{1} \mathrm{~F}_{\mathrm{O}} \mathrm{ATP}$ synthase complex was isolated from $H$. modesticaldum as previously described [3, 32, 33] for the chloroplast ATP synthase. Liquid cultures of $H$. modesticaldum were grown anaerobically using pyruvate-yeast extract medium $(\mathrm{pH}$ 6.9) at $52^{\circ} \mathrm{C}$ under $4,500-6,000$-lux incandescent illumination until the stationary phase is reached [34]. The cells were harvested by centrifugation at $10,000 \mathrm{x}_{\max }$ for $15 \mathrm{~min}$ at $4^{\circ} \mathrm{C}$ and then re-suspended in $200 \mathrm{ml}$ of harvesting buffer containing 50 $\mathrm{mM}$ MOPS ( $\mathrm{pH} 7.0)$ and $5 \mathrm{mM}$ magnesium chloride. The cells were disrupted by sonication with a $100 \%$ duty cycle for 15 cycles at $50 \%$ power using an ultrasonic homogenizer, Model 300 V/T (Biologics Inc., Manassas, Virginia). The lysate was subjected to high-speed centrifugation at 200,000x $\mathrm{g}_{\max }$ for $1 \mathrm{~h}$ at $4{ }^{\circ} \mathrm{C}$, and the membrane pellets were suspended in the harvesting buffer described above. Prior to detergent solubilization, DL-Dithiothreitol (DTT) was added to reach a final concentration of $50 \mathrm{mM}$ and incubated with agitation for $15 \mathrm{~min}$ at $4{ }^{\circ} \mathrm{C}$. The membrane proteins were then solubilized in a buffer containing $20 \mathrm{mM}$ Tricine $(\mathrm{pH}$ 8.0), $200 \mathrm{mM}$ sucrose, $5 \mathrm{mM}$ magnesium chloride, $400 \mathrm{mM}$ ammonium sulfate, $2 \mathrm{mM}$ $\mathrm{Na}_{2}$-ATP, $6.25 \mathrm{mM}$ sodium cholate (Sigma, USA), $12 \mathrm{mM}$ n-octyl- $\beta$-D-glucoside (OG) (GLYCON, Germany), and $50 \mathrm{mM}$ DTT for $15 \mathrm{~min}$ at $4^{\circ} \mathrm{C}$ and then subjected to centrifugation at 200,000x $\mathrm{g}_{\max }$ for $1 \mathrm{~h}$ at $4^{\circ} \mathrm{C}$ to separate solubilized protein-detergent micelles from non-solubilized membranes. The solubilized protein-detergent micelles were precipitated with ammonium sulfate $(45 \%, \mathrm{v} / \mathrm{v})$ at $4^{\circ} \mathrm{C}$. The ammonium sulfate precipitation pellet containing the $\mathrm{HF}_{1} \mathrm{~F}_{\mathrm{O}}$ ATP synthase was re-suspended in buffer containing $30 \mathrm{mM}$ monobasic sodium phosphate (pH 7.2), $200 \mathrm{mM}$ sucrose, $2 \mathrm{mM}$ magnesium chloride, $0.5 \mathrm{mM} \mathrm{Na} 2$-EDTA, and $4 \mathrm{mM}$-dodecyl- $\beta$-D-maltopyranoside $(\beta$-DDM) (GLYCON, Germany) and was further purified by sucrose density gradient centrifugation at $242,000 \mathrm{x}$ g for $17 \mathrm{~h}$ at $44^{\circ} \mathrm{C}$ in gradient buffer containing $30 \mathrm{mM}$ monobasic sodium phosphate $(\mathrm{pH} 7.2), 2 \mathrm{mM}$ magnesium chloride, $0.5 \mathrm{mM}$ $\mathrm{Na}_{2}$-EDTA, $8 \mathrm{mM} \beta$-DDM, $1 \mathrm{mg} / \mathrm{ml}$ asolectin and sucrose at a concentration range from $20-60 \%(\mathrm{w} / \mathrm{v})$. The fractions from the sucrose density gradient were collected from the bottom to the top of the gradient. The sucrose was removed by using Sephadex G-25 desalting columns at $4^{\circ} \mathrm{C}$ previously equilibrated in buffer containing $10 \mathrm{mM}$ Tricine ( $\mathrm{pH} 8.0$ ), $5 \mathrm{mM}$ magnesium chloride, and $8 \mathrm{mM} \beta$-DDM and the ATP synthase was concentrated with a $100-\mathrm{kDa}$ cutoff concentrators membrane filter devices (Millipore, Billerica, MA) prior to further experiments. The protein concentration was determined according to the modified Lowry method $[35,36]$. 


\section{Protein analysis by electrophoresis techniques}

The subunit composition of the $\mathrm{HF}_{1} \mathrm{~F}_{\mathrm{O}}$ ATP synthase was analyzed using $15 \%$

Tricine-SDS-PAGE polyacrylamide gels, according to Schagger [37] with a few modifications: protein samples were diluted at a 1:2 ratio with sample loading buffer (62.5 mM Tris- $\mathrm{HCl}$ (pH 6.8), $2 \%$ SDS, $25 \%$ glycerol, $0.01 \%$ bromophenol blue), and incubated at $80^{\circ} \mathrm{C}$ for $30 \mathrm{~min}$ to completely disassemble the c-ring of ATP synthase. The gels were run at $4^{\circ} \mathrm{C}$ for $3 \mathrm{~h}$.

The intact $\mathrm{HF}_{1} \mathrm{~F}_{\mathrm{O}}$ ATP synthase was analyzed using $4-16 \%$ native polyacrylamide gels as previously described [38, 39] with modifications: protein samples, in the presence of $\beta$-DDM at $8 \mathrm{mM}$, were mixed with $2 \mathrm{X}$ native sample buffer (100 mM sodium chloride, $100 \mathrm{mM}$ imidazole- $\mathrm{HCl}, 4 \mathrm{mM}$ 6-aminohexanoic acid, 10\% glycerol, $2 \mathrm{mM}$ EDTA (pH 7.0)). Subsequently, protein samples for blue native gel electrophoresis (BN-PAGE) and high-resolution clear native gel electrophoresis (hrCN-PAGE) were additionally supplemented with Coomassie Blue G-250 dye (a detergent/Coomassie ratio of 8$)$ and Ponceau $\mathrm{S}(0.01 \%)$, respectively. The native electrophoretic buffers were identical except that the BN-PAGE cathode buffer contained the anionic Coomassie Blue G-250 dye (0.02\%), and the hrCN-PAGE cathode buffer contained two detergents $(0.05 \%)$ sodium deoxycholate (Sigma, USA) and $0.01 \%$ non-ionic $\beta$-DDM). Native gel electrophoresis was performed at $4{ }^{\circ} \mathrm{C}$ to maintain protein-complex integrity.

Protein bands were visualized with either the Coomassie Blue staining method or the Silver staining method [40]. Heme-containing proteins were detected with the heme staining method [41]. For immunoblot analysis, performed in principle as previously described [42], the proteins were transferred onto a PVDF membrane in a buffer optimized for the transfer of ATP synthase subunits $(25 \mathrm{mM}$ Tris base, $192 \mathrm{mM}$ glycine, $0.1 \%$ SDS, and $20 \%$ methanol). The membrane was blocked in 5\% non-fat milk containing $50 \mathrm{mM}$ Tris-Base, $150 \mathrm{mM}$ sodium chloride, and $0.05 \%$ Tween-20 for $1 \mathrm{~h}$ and then incubated with primary antibodies (AptA and AptH, 1:10,000, Agrisera, Sweden) in $5 \%$, non-fat dry milk in $1 \mathrm{X}$ Tris-buffered saline with Tween-20 (TBST buffer), containing $50 \mathrm{mM}$ Tris- $\mathrm{HCl} \mathrm{pH} 8.0,150 \mathrm{mM}$ sodium chloride, $0.05 \%$ Tween-20), washed three times with $1 \mathrm{X}$ TBST, incubated with goat anti-rabbit IgG-HRP -conjugated secondary antibodies $(1: 5,000)$, washed again, and stained with the Immun-Star HRP substrate reagent.

\section{ATP hydrolysis activity in-gel assay}

The in-gel assay of ATP hydrolysis activity was performed as previously described [16] with modifications, as follows: hrCN-PAGE gel strips were pre-equilibrated in 
$40 \mathrm{mM}$ Tris- $\mathrm{HCl}, 4 \mathrm{mM}$ ATP, and $1.5 \mathrm{mM}$ magnesium chloride ( $\mathrm{pH}$ 8.0) supplemented with $30 \mathrm{mM}$ of various detergents, including beta-dodecylmaltoside ( $\beta$-DDM) (Glycon), $\beta$-octylglycoside (OG) (Glycon), $\mathrm{N}, \mathrm{N}$-dimethyl-1-dodecanamine-N-oxide (LDAO) (Affymetrix/Anatrace), or tauro-deoxycholate (TDOC) (Sigma-Aldrich), for 3 hours at room temperature. Following removal of the incubation solution and a 1-min brief rinse with deionized water, the gel strips were incubated in an assay buffer comprising $35 \mathrm{mM}$ Tris- $\mathrm{HCl}$, $270 \mathrm{mM}$ glycine, $14 \mathrm{mM}$ magnesium sulfate, $0.075 \%$ lead nitrate, and $0.8 \mathrm{mM}$ ATP (pH 7.8) with $20 \%$ methanol at room temperature for $30 \mathrm{~min}, 60 \mathrm{~min}$ and for $24 \mathrm{~h}$. Increasing ATP hydrolysis activity leads to increasing lead phosphate precipitate formation. For imaging, the reaction was stopped with $50 \%$ methanol. The gel strips were incubated for $30 \mathrm{~min}$ and then rinsed with deionized water. The transparent gel strips were imaged on top of a blue background to improve the visibility of the lead nitrate bands. 


\section{Results and discussion}

\section{Purification and subunit composition of the $F_{1} F_{O}$-ATPase from}

\section{H. modesticaldum}

Since the discovery of heliobacteria, remarkable progress has been made in the understanding of their physiology and energy metabolism, as well as in the characterization of their photosynthetic reaction center, including the pigment composition and electron transfer reactions [1, 33, 43-47]. Heliobacteria differ from many other photosynthetic organisms as they lack differentiated internal membranes or membrane-bound vesicles. Therefore, the cytoplasmic membrane is the only membrane system found in Heliobacteria [48]. All membrane-bound complexes, including all photosynthetic complexes and a large number of various transporters for transporting essential substrates into the cells, are confined to this cytoplasmic membrane[2,48]. According to the complete genome sequence analysis of $H$. modesticaldum [49], a gene cluster was identified for the ATP synthase that contains all eight subunits and it is assumed that the enzyme is present in the cytoplasmic membrane $[2,49]$.

The primary aim of this study was to establish a method to purify the intact ATP synthase complex from $H$. modesticaldum for further bioenergetic and structural studies.

Studies aimed to isolate the photosynthetic reaction center of $H$. modesticaldum used a low percentage of either $\beta$-DDM or $\beta$-DM to extract the photosynthetic reaction center from the membrane[33, 50]. We modified the protocol developed for the photosynthetic RC by varying the nature of the detergents as well as their concentrations, taking into account procedures established for the chloroplast enzyme from plants and the ATP synthase from cyanobacteria. The maximal yield of ATP synthase extracted from cytoplasmic membranes was obtained using a detergent mixture of $6.25 \mathrm{mM}$ cholate and $15 \mathrm{mM} \mathrm{OG}$, as described in the materials and methods section. Subsequently, the ATP synthase complex was precipitated by ammonium sulfate fractionation at $45 \%(\mathrm{v} / \mathrm{v})$ saturated ammonium sulfate solution at $4^{\circ} \mathrm{C}$ (Figure 1, lane 2). The fraction also contained a lower amount of heme-containing proteins (cyt $\mathrm{c}_{533}$ ), as shown in Figure 2, lane 7. However, these contaminating heme-proteins were removed by the subsequent sucrose gradient centrifugation step (Figure 2, lane 9). To increase enzymatic stability and activity[32], the two detergents used in the initial solubilization step (cholate and OG) were replaced by $8 \mathrm{mM} \beta$-DDM during the sucrose density gradient centrifugation. 
As determined by silver-stained SDS-PAGE, the ATP synthase complex is essential in the interfacial fractions between $44 \%$ and $52 \%$ of the sucrose gradient (Figures 3 and 4). Tricine SDS-PAGE electrophoresis of the isolated ATP synthase complex showed the typical subunit pattern of an F-ATP synthase (Figure 5, lane 3), with five $\mathrm{F}_{1}$ subunits ( $\alpha, \beta, \gamma, \delta$ and $\varepsilon$ ), and three $\mathrm{F}_{\mathrm{O}}$ subunits ( $\mathrm{a}, \mathrm{b}$ and $\mathrm{c}$ ), according to the molecular mass pattern of the chloroplast enzyme $\mathrm{CF}_{1} \mathrm{~F}_{\mathrm{O}}$, which was used as a positive control in the SDS-PAGE analysis (Figure 5, lane 2). The identities of the $\alpha$-subunit (AtpA) and the c-subunit (AtpH) of $\mathrm{HF}_{1} \mathrm{~F}_{\mathrm{O}}$ were confirmed by western blotting, as shown in Figure 5, lanes 4 and 5.

\section{Native gel electrophoresis}

The quaternary structure of $\mathrm{HF}_{1} \mathrm{~F}_{\mathrm{O}}$ was analyzed in more detail by native gel electrophoresis. This technique has been previously used to analyze ATP synthase complexes of mitochondria and chloroplasts. It has also been applied to the analysis of enzymatically active oligomeric states [51-55] or in advanced structural studies using 2D-crystallization and electron microscopic single particle analysis of proteins extracted from BN-PAGE[53, 56-58].

The isolated $\mathrm{HF}_{1} \mathrm{~F}_{\mathrm{O}}$-ATP synthase complex was analyzed by native electrophoresis techniques to investigate whether it forms oligomers. In-gel activity assays were performed to test if the complex still retains its physiologically functional state after the isolation procedure.

Under the conditions of native gel electrophoresis, the integral $\mathrm{HF}_{1} \mathrm{~F}_{\mathrm{O}}$-ATP synthase complexes migrated as a band with an apparent molecular mass of $600 \mathrm{kDa}$ in both BN-PAGE and hrCN-PAGE gels and was identified as a monomeric complex according to the native electrophoretic mobility of the $\mathrm{CF}_{1} \mathrm{~F}_{\mathrm{O}}$ complex in BN-PAGE, as previously described [59-61] (Figure 6, panel A). The heliobacterial ATP synthase appears to be more stable than the chloroplast enzyme under the stress of the native gel electrophoresis: a significant band for the chloroplast $\mathrm{CF}_{1}$ subcomplex was identified just below $480 \mathrm{kDa}$ in both BN-PAGE and hrCN-PAGE gels (Figure 6, panel $\mathrm{A}$, lanes 2 and 4 ); however, in the region of the identified $\mathrm{CF}_{1}$ subcomplex, only a weak band for the $\mathrm{HF}_{1}$ is identified with Coomassie Blue staining. The gel strips of hrCN-PAGE containing $\mathrm{HF}_{1} \mathrm{~F}_{\mathrm{O}}$-ATP synthase complexes were further analyzed using two-dimensional electrophoresis (1-D hrCN-PAGE, 2-D SDS-PAGE), which identified the individual subunits of the $\mathrm{HF}_{1} \mathrm{~F}_{\mathrm{O}}$ complex on 2-D SDS-PAGE according to the molecular mass shown in Figure 6, panel $\mathrm{B}$. The $\mathrm{HF}_{1} \mathrm{~F}_{\mathrm{O}}$ complex contains all 
$\mathrm{HF}_{1}$ and $\mathrm{HF}_{\mathrm{O}}$ subunits.

\section{Biochemical properties of the isolated ATP synthase from $H$. modesticaldum}

The ATP synthesis and hydrolysis functions of ATP synthases isolated from different sources has been studied most frequently via liposome reconstitution and chemiosmotic $\mathrm{pH}$ jump experiments. However, the techniques involved are complex and time consuming as they study the function of the enzyme after detergent removal in lipid bilayers. However, these methods cannot analyze the catalytic function of the ATP synthase in form of a protein-detergent complex.

Therefore, the combination of native gel electrophoresis techniques and an in-gel functional activity assay has evolved into a powerful tool for protein-protein interaction analysis in mitochondrial respiratory complexes [62]. One of the established in-gel assays, named here the "in-gel ATP hydrolysis assay," was remarkably useful in both qualitative and quantitative analyses of the catalytic activity of the mitochondrial ATP synthase (complex V) [38]. Because ATP hydrolysis activity can be monitored in native gels via an in-gel ATPase assay, it can be used to rapidly screen for enzymatic activity of the isolated ATP synthase complex in detergents directly in the gel without involving reconstitution into liposomes. We used this assay to screen for the best detergent to stabilize the structure and function of the heliobacterial ATP synthase in different protein-detergent complexes. This is not possible using ATP synthesis assays, as they all require removal of the detergent during reconstitution into lipid membranes.

The functional properties of the isolated $\mathrm{HF}_{1} \mathrm{~F}_{\mathrm{O}}$-ATP synthase complex were examined by monitoring the ATP hydrolysis activity by observing lead phosphate precipitate formation using the in-gel ATPase activity assay at room temperature, as previously described [16].

For the in-gel ATPase activity assay, hrCN-PAGE is highly preferred compared with BN-PAGE because the dye Coomassie Blue applied on BN-PAGE can dissociate detergent-labile subunits from the super-complex or disassemble the super-complex into sub-complexes. Furthermore, lead precipitate detection is very difficult in the presence of the Coomassie Blue dye. The hrCN-PAGE gels are colorless; therefore, the in-gel assays can be directly performed without any interference with the Coomassie Blue dye $[38,55,62,63]$. 
We compared the $\mathrm{CF}_{1} \mathrm{~F}_{\mathrm{O}}$ isolated from spinach chloroplast with the $\mathrm{HF}_{1} \mathrm{~F}_{\mathrm{O}}$ complex isolated from $H$. modesticaldum. Previous studies provided that ATP hydrolysis activity of the chloroplast $\mathrm{CF}_{1} \mathrm{~F}_{\mathrm{O}}$-ATP synthase complex is extremely low, but can be improved by activating the $\mathrm{CF}_{1} \mathrm{~F}_{\mathrm{O}}$-ATP synthase complex via detergent treatments prior to the in-gel ATPase activity assay [16, 29, 30]. One interesting question was if the heliobacterial ATP synthase would require activation or if the intact enzyme was fully functional for ATP hydrolysis without any activation such as harsh detergent treatment. hrCN-PAGE gel strips were treated with selected detergents as described in detail in materials and methods section. We tested the ATP hydrolysis activity of the chloroplast and $H$. modesticaldum ATP synthase in the presence of the following detergents: OG (octyl-glucoside) a non-ionic short length detergent, $\beta$-DDM (beta-dodecylmaltoside ) a mild non-ionic long chain detergent, LDAO (N,N-dimethyl-1-dodecanamine-N-oxide) an ionic mild long chain detergent, and TDOC (tauro-deoxycholate) a harsh detergent.

Using OG treatment, ATP hydrolysis could not be detected for either $\mathrm{CF}_{1} \mathrm{~F}_{\mathrm{O}}$ or $\mathrm{CF}_{1}$ within the $0.5 \mathrm{~h}$ or $1 \mathrm{~h}$ incubation periods (Figure 7 , A panel, lane 1 and lane 3 ). After 24 hours of incubation, extremely weak bands indicating hydrolysis activity were visible (Figure 7, A panel, lane 5). For ATP $\mathrm{HF}_{1} \mathrm{~F}_{\mathrm{O}}$ hydrolysis of the intact enzyme was already detectable as a weak band after an incubation period of $0.5 \mathrm{~h}$ (Figure 7, A panel, lane 2). The intensity of the band increased after 1 hour, and saturated activity was observed after an incubation period of $24 \mathrm{~h}$ (Figure 7, A panel, lane 6).

Interestingly, weak $\mathrm{HF}_{1}$ hydrolysis activity was only visible after an incubation period of $24 \mathrm{~h}$.

Using $\beta$-DDM, no ATP hydrolysis of the chloroplast ATP synthase, $\mathrm{CF}_{1} \mathrm{~F}_{\mathrm{O}}$, was detected after incubation times of $0.5 \mathrm{~h}$ and $1 \mathrm{~h}$ (Figure 7, B panel, lane 1 and lane 3), whereas a subcomplex of the chloroplast enzyme showed strong ATP-hydrolysis activity already after $0.5 \mathrm{~h}$ and $1 \mathrm{~h}$. In contrast, strong $\mathrm{HF}_{1} \mathrm{~F}_{\mathrm{O}}$ ATP hydrolysis activity was already observed after an incubation time of $0.5 \mathrm{~h}$ (Figure 7, B panel, lane 2), and the band was even more pronounced after the $1 \mathrm{~h}$ incubation period. (Figure 7, B panel, lane 4). In contrast to the chloroplast $\mathrm{CF}_{1} \mathrm{~F}_{\mathrm{O}}$ subcomplex, the $\mathrm{HF}_{1}$ subcomplex showed no hydrolysis activity after $0.5 \mathrm{~h}$ and $1 \mathrm{~h}$; a weak band became visible only after the $24 \mathrm{~h}$ incubation period. This is a very interesting result because it indicates that the intact $\mathrm{HF}_{1} \mathrm{~F}_{\mathrm{O}}$ is fully active in the ATP hydrolysis direction in the presence of very mild detergents such as $\beta$-DDM without requiring activation. Furthermore, the results indicate that removal of the proton-translocating $\mathrm{HF}_{\mathrm{O}}$ domain blocks ATP hydrolysis, as only very weak ATP hydrolysis was detected after $24 \mathrm{~h}$ for $\mathrm{HF}_{1}$ in 
$\beta-\mathrm{DDM}$.

Using LDAO, only very weak ATP hydrolysis activity of the chloroplast $\mathrm{CF}_{1} \mathrm{~F}_{\mathrm{O}}$ and $\mathrm{CF}_{1}$ was detected after 0.5 and $1 \mathrm{~h}$, whereas $\mathrm{HF}_{1} \mathrm{~F}_{\mathrm{O}}$ showed very high activity (Figure 7, C panel, lanes 1 and lane 2). Interestingly, also using LDAO, no $\mathrm{HF}_{1}$ hydrolysis activity was detected after 0.5 and $1 \mathrm{~h}$, and only a weak band appeared after an incubation period of $24 \mathrm{~h}$ (Figure 7, C panel, lane 6).

In contrast to the results of the ATP synthase complexes treated with the detergents OG, $\beta$-DDM and LDAO, both $\mathrm{CF}_{1} \mathrm{~F}_{\mathrm{O}}$ and $\mathrm{HF}_{1} \mathrm{~F}_{\mathrm{O}}$ treated with the harsh detergent TDOC showed extremely low ATP hydrolysis activities after the $0.5 \mathrm{~h}$ and $1 \mathrm{~h}$ incubation periods (Figure 7, D panels, lanes 1, 2, 3, and 4), and significant activity could only be detected after 24 hours of incubation (Figure 7, D panel, lanes 5 and lane 6).

In summary, these results indicate that $\mathrm{HF}_{1} \mathrm{~F}_{\mathrm{O}}$ shows high ATPase activity in mild detergents such as LDAO and $\beta$-DDM, whereas extremely low ATP hydrolysis activity was detected in harsher detergents such as OG and TDOC.

The fastest and highest ATP hydrolysis activity observed was detected when $\mathrm{HF}_{1} \mathrm{~F}_{\mathrm{O}}$ was treated with LDAO. This result may indicate that long-chain detergents such as $\beta$-DDM and especially LDAO, which are known to stabilize membrane protein complexes, stabilize $\mathrm{HF}_{1} \mathrm{~F}_{\mathrm{O}}$ and maintain its full catalytic activity. In contrast, short-chain detergents such as OG and TDOC may destabilize the heliobacterial ATP synthase and thereby inactivate it. In contrast to the chloroplast enzyme, for which $\mathrm{CF}_{1}$ shows much higher ATP hydrolysis activity that $\mathrm{CF}_{1} \mathrm{~F}_{\mathrm{O}}$, the detachment of the head of the heliobacterial ATP synthase $\left(\mathrm{HF}_{1}\right)$ from the intact enzyme does not enhance but rather inhibits ATP hydrolysis activity. Such behavior has thus far not been reported for F-type ATP synthases but has been reported for vacuolar type V ATPases, which are enzymes that function to establish an $\mathrm{H}^{+}$gradient across the membrane [64].

Our results may provide preliminary evidence that the heliobacterial ATP synthase may act in vivo in both ATP synthesis and ATP hydrolysis and that a mechanism may exist in Heliobacterium modesticaldum that leads to switching off of the ATP hydrolysis function when the $\mathrm{HF}_{1}$ head is decoupled from the transmembrane $\mathrm{HF}_{0}$ proton inducing channel. 


\section{Conclusion}

The combination of a modified isolation method and in-gel ATPase activity assay reported here confirmed that isolation of the functionally intact ATP synthase under anaerobic condition from anaerobic Heliobacterium modesticaldum cells can be achieved. We have shown that approximately $20 \mathrm{mg}$ of purified ATP synthase can be routinely obtained from $4 \mathrm{~L}$ of anaerobic cell culture. The most critical breakthroughs in achieving these results were modifications in the way the cells were broken down as well as modifications in the isolation of the protein from the membrane. The in-gel ATPase activity assay for the ATP synthase of $H$. modesticaldum allowed us to detect ATP hydrolysis activity directly in the gel and to identify the stability and activity of the ATP synthase in different detergent micelles. The use of the in-gel activity assay method not only offers an expeditious way to screen for activity of sample fractions in a high-throughput manner but also allows for the assessment of the stability and activity of different ATP synthase subcomplexes in different detergents. The intact heliobacterial $\mathrm{HF}_{1} \mathrm{~F}_{\mathrm{O}}$ enzyme shows fully active ATP hydrolysis activity in mild detergents, whereas the ATP hydrolysis activity is inactivated when the $\mathrm{HF}_{1}$ head is removed from the $\mathrm{HF}_{\mathrm{O}}$ transmembrane part of $\mathrm{HF}_{1} \mathrm{~F}_{\mathrm{O}}$.

Our reported methods provided a primary isolation process under strictly anaerobic conditions, thereby providing heliobacterial ATP synthase samples for further studies that will include in particular bioenergetics studies, crystallization experiments, and may also be applied to ATP synthases from other anaerobic organisms in the future.

\section{Acknowledgments}

The work in the laboratory of Petra Fromme was supported by the National Institutes of Health (grant no GM081490 and GM095583) and the BioXFEL Science and Technology Center funded by the National Science Foundation (award 1231306). The work the laboratory of Kevin E. Redding was funded by the Division of Chemical Sciences, Geosciences and Biosciences, Office of Basic Energy Sciences of the U.S. Department of Energy through grant DE-SC0010575. JH was also supported by the Galvin Chair award to PF from Arizona State University.

We also thank Patricia Baker from Dr. Redding's lab for helpful guidance and discussion concerning of $H$. modesticaldum cell culture. 


\section{Figures:}

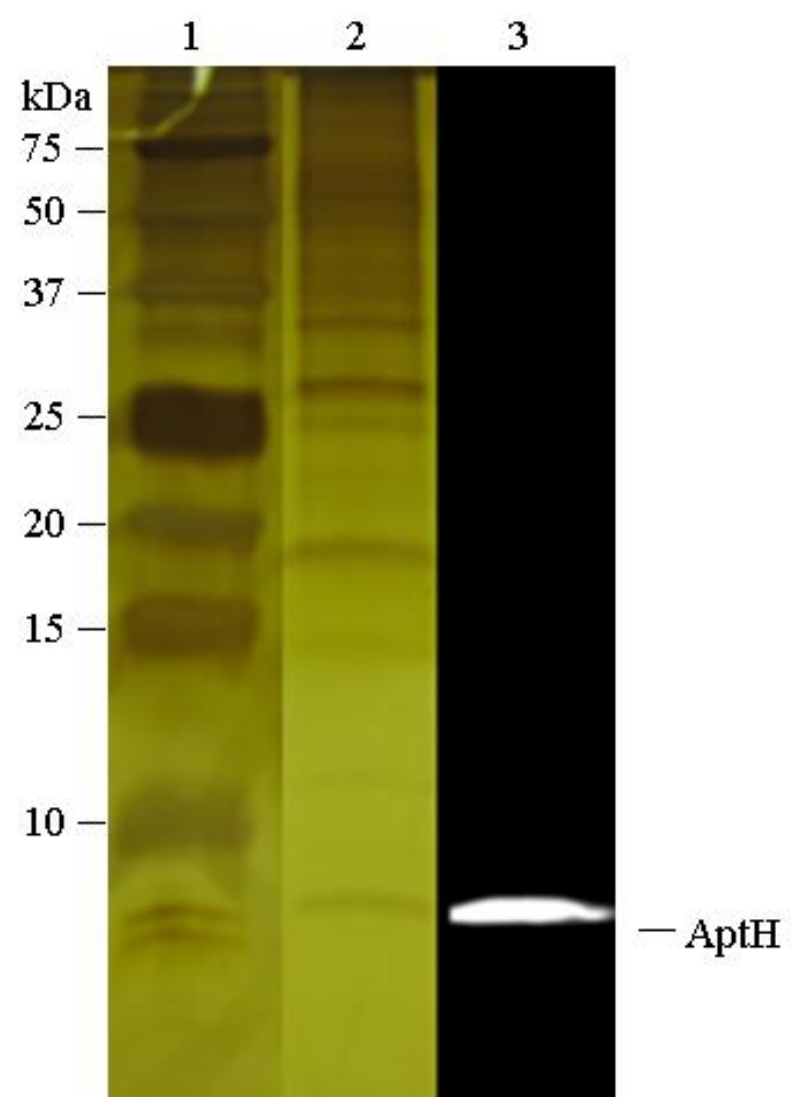

Figure 1. Tricine-SDS polyacrylamide gel and immunoblot analysis of the $45 \%$ (v/v) ammonium sulfate precipitate fraction of solubilized membrane proteins of $H$. modesticaldum.

The silver-stained 15\% Tricine-SDS polyacrylamide gel and immunoblotting detection of the 8-kDa c-subunit (AptH), shows $\mathrm{HF}_{1} \mathrm{~F}_{\mathrm{O}}$-ATP synthase complex was enriched in the $45 \%(\mathrm{v} / \mathrm{v})$ saturated ammonium sulfate $\left(\left(\mathrm{NH}_{4}\right)_{2} \mathrm{SO}_{4}\right)$ fraction (lanes 2 and 3, respectively). [lane 1, $\mathrm{kDa}$, protein dual color standards (Bio-Rad, USA); lane $2,45 \%$ (v/v) ammonium sulfate precipitate fraction in 15\% Tricine-SDS-PAGE; lane $3,45 \%(\mathrm{v} / \mathrm{v})$ Western-blot of the ammonium sulfate precipitate fraction using the AptH antibody against the C-subunit of the $H$. modesticaldum ATP synthase]. 


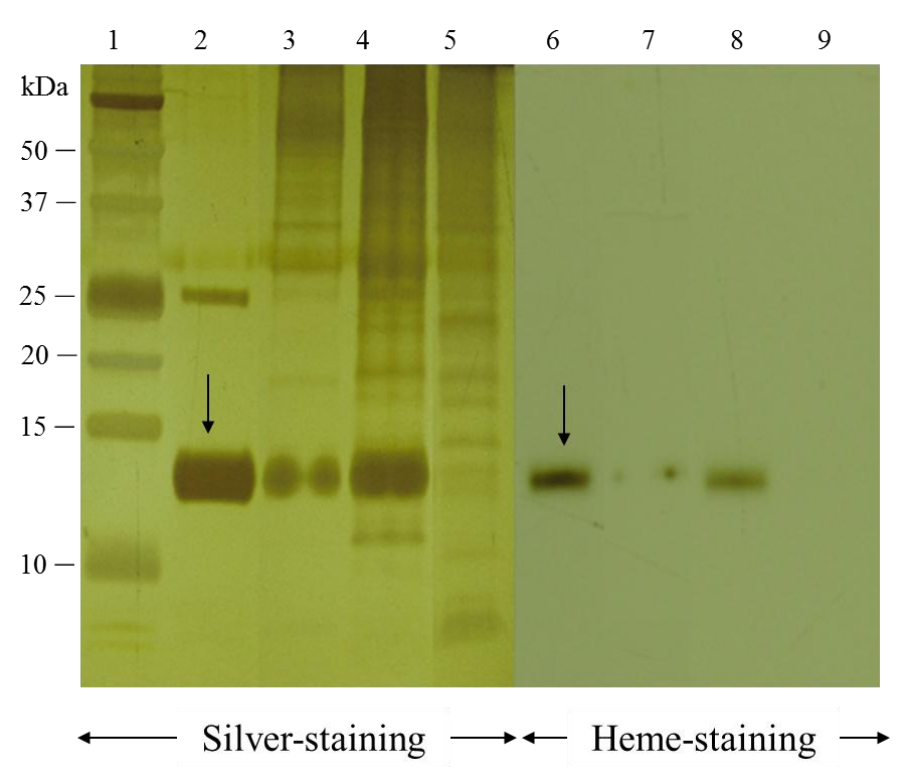

Figure 2. Analysis of the ammonium sulfate fractions of the ATP synthase extract by denaturing electrophoresis.

Silver-stained and heme-stained Tricine-SDS polyacrylamide gel analysis of different fractions collected from the ammonium sulfate precipitation steps and the discontinuous sucrose density gradient centrifugation of $H$. modesticaldum. The fractions ${ }^{45 \%(4 \mathrm{P}), 60 \%(6 \mathrm{P}) \text {, and } 44 \%(\mathrm{SG})}$ were analyzed by $15 \%$ Tricine-SDS-PAGE electrophoresis with silver staining (lanes 3, 4 and 5) and heme staining (lanes 7, 8, and 9). The heme staining indicated that fraction ${ }^{45 \%(4 P)}$ (lanes 3 and 7) and fraction ${ }^{60 \%(6 \mathrm{P})}$ (lanes 4 and 8) are contaminated by 14-kDa cytochrome $c$ according to the molecular mass of the positive control (lanes 1 and 6) cytochrome c (see arrow)[33]. The majority of cyt. $c$ was precipitated by the $60 \%(\mathrm{v} / \mathrm{v})$ saturated ammonium sulfate solution (fraction ${ }^{60 \%(6 \mathrm{P})}$, lanes 4 and 8). The fraction ${ }^{45 \%(4 \mathrm{P})}$ enriched the intact $\mathrm{HF}_{1} \mathrm{~F}_{\mathrm{O}}$ ATP synthase still contained minimal amount of cyt. $c$, which was removed via discontinuous sucrose density gradient centrifugation. Lane 9 shows the $44 \%$ sucrose fraction from the density gradient, which contained intact $\mathrm{HF}_{1} \mathrm{~F}_{\mathrm{O}}$ ATP synthase without cyt. $c$ contamination.

[lane 1, protein dual color standards (Bio-Rad, USA); lanes 2 and 6, positive control, cytochrome c (provided by Dr. Sarrou); lanes 3 and 7, fraction ${ }^{45 \%(4 P),}$ proteins fractionated by $45 \%(\mathrm{v} / \mathrm{v})$ saturated ammonium sulfate solution; lanes 4 and 8 , fraction $^{60 \%(6 \mathrm{P}),}$ proteins fractionated by $60 \%(\mathrm{v} / \mathrm{v})$ saturated ammonium sulfate solution; lanes 5 and 9 , fraction ${ }^{44 \%(\mathrm{SG})}$, fractions collected between $44 \%$ from the sucrose gradient. Abbreviations: P, pellets; SG, sucrose density gradient]. 


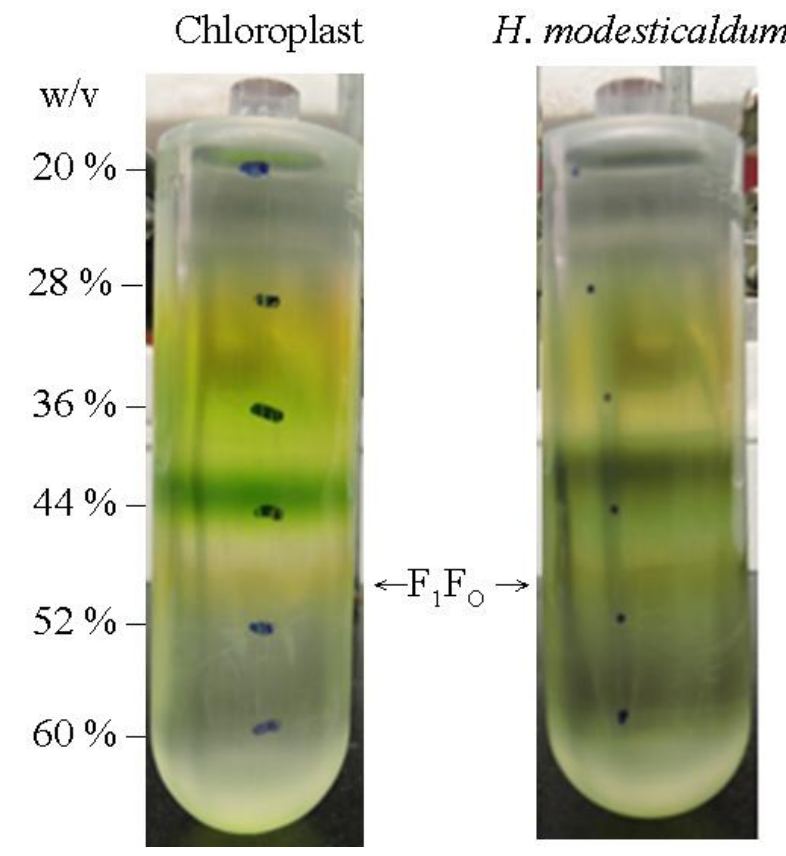

Figure 3. Discontinuous sucrose density gradient centrifugation of the ATP synthase form chloroplast (left) and H. modesticaldum (right).

The intact ATP synthase was separated from other membrane proteins using discontinuous sucrose density gradient centrifugation. The interface fraction between $44 \%$ and $52 \%$ contains the ATP synthases.The yellowish fraction from the isolated fraction form chloroplast (left) contains chloroplast $\mathrm{CF}_{1} \mathrm{~F}_{\mathrm{O}}$ ATP synthase, which were isolated according to the method previously described [32].The olive greenish fraction of the isolated fraction (right) of the $H$. modesticaldum contains the $\mathrm{HF}_{1} \mathrm{~F}_{\mathrm{O}}$ ATP synthase. The indicated numbers on the right represent the concentration of sucrose $(w / v)$ in each fraction of the step gradient. 


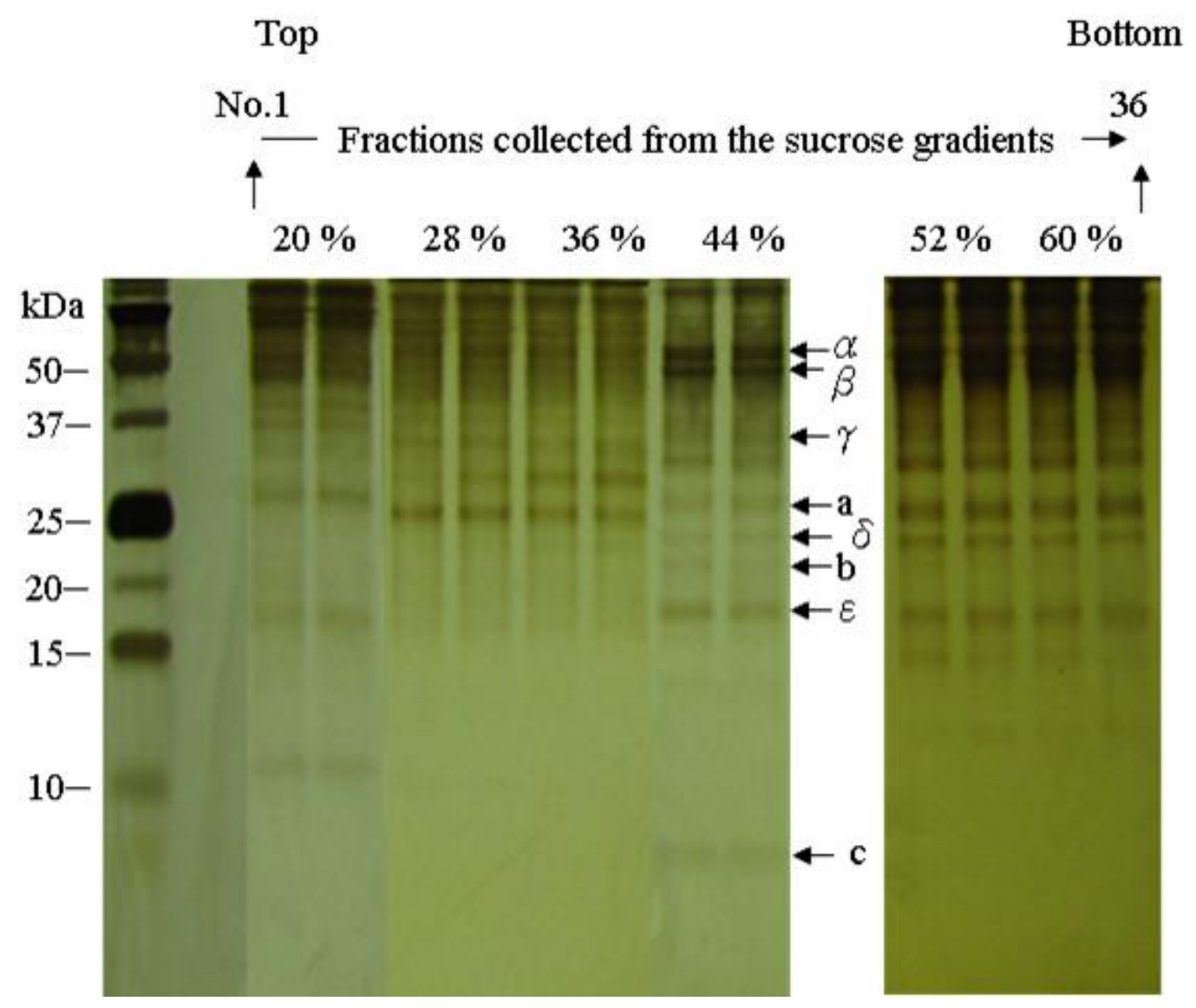

Figure 4. Silver-stained 15\% Tricine-SDS polyacrylamide gel of the total proteins in the collected sucrose gradient fractions.

The analysis showed that the interface fractions between $44 \%$ and $52 \%$ were enriched in $H$. modesticaldum $\mathrm{HF}_{1} \mathrm{~F}_{\mathrm{O}}$ ATP synthase, indicated by arrow that represents the c-subunit of $\mathrm{HF}_{1} \mathrm{~F}_{\mathrm{O}} \mathrm{ATP}$ synthase. 


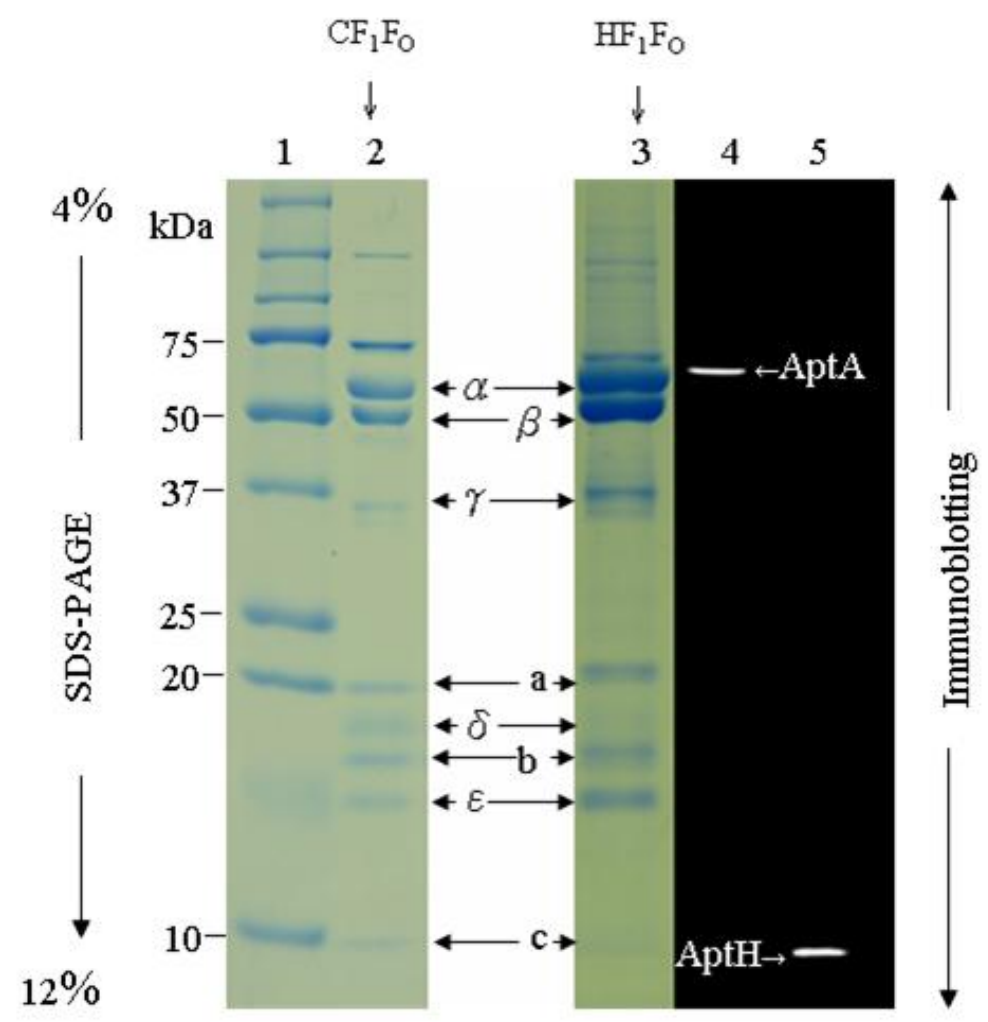

Figure 5. Tricine-SDS polyacrylamide gel electrophoresis and immunoblot analysis ofthe $H$. modesticaldum $\mathrm{HF}_{1} \mathrm{~F}_{\mathrm{O}}$ ATP synthase.

The 5 subunits $\left(\alpha, \beta, \gamma, \delta\right.$, and $\varepsilon$ ) of the $\mathrm{HF}_{1}$ subcomplex and the 3 subunits (a, b, and c) of the $\mathrm{HF}_{\mathrm{O}}$ subcomplex of the $H$. modesticaldum $\mathrm{HF}_{1} \mathrm{~F}_{\mathrm{O}}$ ATP synthase complex were identified (lane 3 ) according to the molecular mass of each subunit and a compared to the positive control chloroplast $\mathrm{CF}_{1} \mathrm{~F}_{\mathrm{O}}$ ATP synthase (lane 2). The immunoblot detectsthe $\sim 52-\mathrm{kDa} \alpha$ subunit of the $\mathrm{HF}_{1}$ subcomplex (lane 4 ) and the $\sim 8-\mathrm{kDa} \mathrm{c}$ subunit of the $\mathrm{HF}_{\mathrm{O}}$ subcomplex (lane 5). [lane 1, protein dual color standards (Bio-Rad, USA); lane 2, positive control, chloroplast $\mathrm{CF}_{1} \mathrm{~F}_{\mathrm{O}}$ ATP synthase complex; lanes $3 \mathrm{H}$. modesticaldum $\mathrm{HF}_{1} \mathrm{~F}_{\mathrm{O}} \mathrm{ATP}$ synthase complexes collected from the interface gradient between $44 \%$ and $52 \%(\mathrm{w} / \mathrm{v})$ of the sucrose gradient; Lanes 4 and 5 , Western blot analysis with antibodies against the $\alpha$-subunit (AptA) ans c-subunit (AtpH)]. 
A.

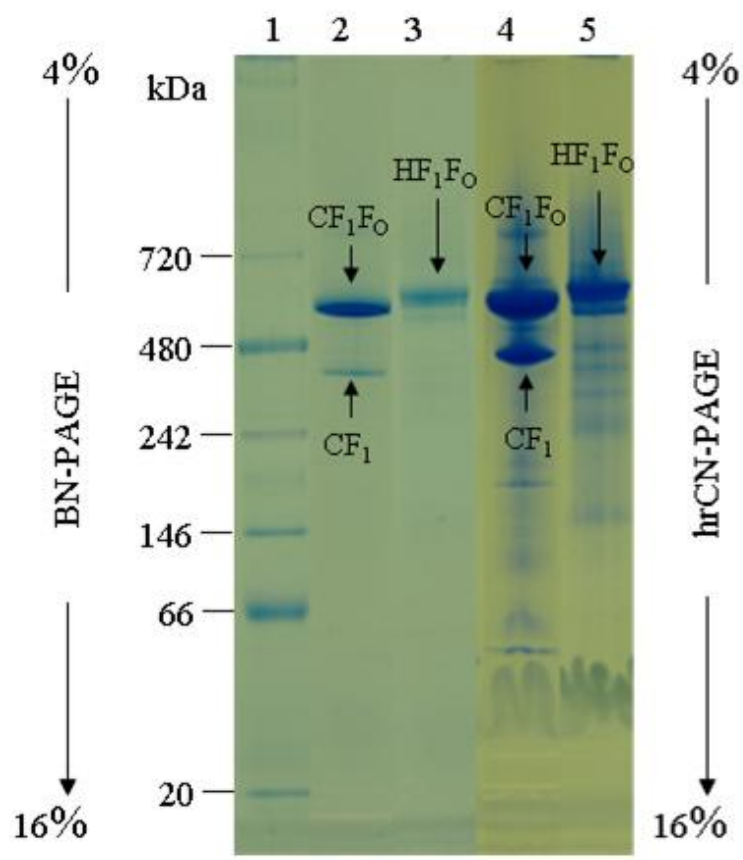

B.

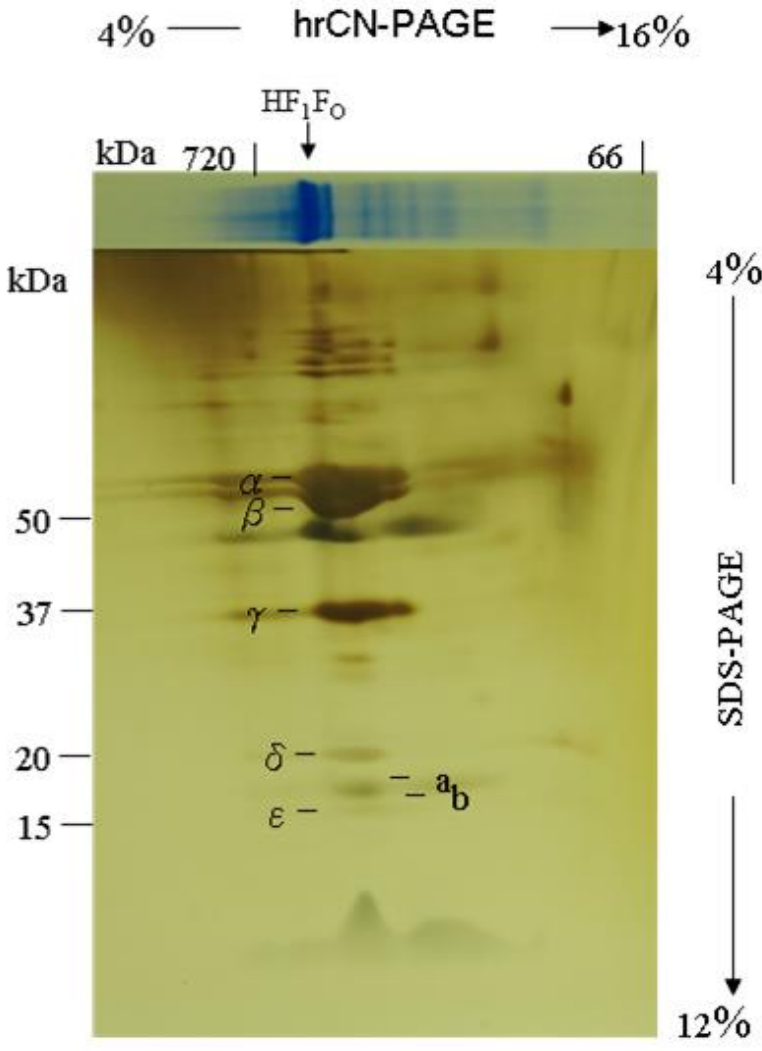

Figure 6. Native gel electrophoresis analysis and 2D-electrophoresis analysis of the $\beta$-DDM-solubilized intact ATP synthase complex of H. modesticaldum.

(A) The intact $F_{1} F_{O}$ complexes and $F_{1}$ subcomplexes were identified on the gels of blue native electrophoresis (BN-PAGE) (lanes 2 and 3) and high-resolution clear native electrophoresis (hrCN-PAGE) (lane 4 and 5). Lanes 4 and 5 which represent the clear native gel were stained with Coomassie Blue after completion of the electrophoresis run. (B) A hrCN-PAGE gel strip of the H. modesticaldum $\mathrm{HF}_{1} \mathrm{~F}_{\mathrm{O}}$ ATP synthase complex was analyzed by $2 \mathrm{D}$ electrophoresis, which showed all individual subunits of the $H$. modesticaldum $\mathrm{HF}_{1} \mathrm{~F}_{\mathrm{O}}$ ATP synthase complex. [lane 1, unstained native protein standard (Life Technologies, USA); lane 2, BN-PAGE of the chloroplast $\mathrm{CF}_{1} \mathrm{~F}_{\mathrm{O}}$ ATP synthase complex; lane 3, BN-PAGE of the H. modesticaldum $\mathrm{HF}_{1} \mathrm{~F}_{\mathrm{O}}$ ATP synthase complex; lane 4 , hrCN-PAGE of the chloroplast $\mathrm{CF}_{1} \mathrm{~F}_{\mathrm{O}}$ ATP synthase complex; lane 5, hrCN-PAGE of the $H$. modesticaldum $\mathrm{HF}_{1} \mathrm{~F}_{\mathrm{O}}$ ATP synthase complex]. 


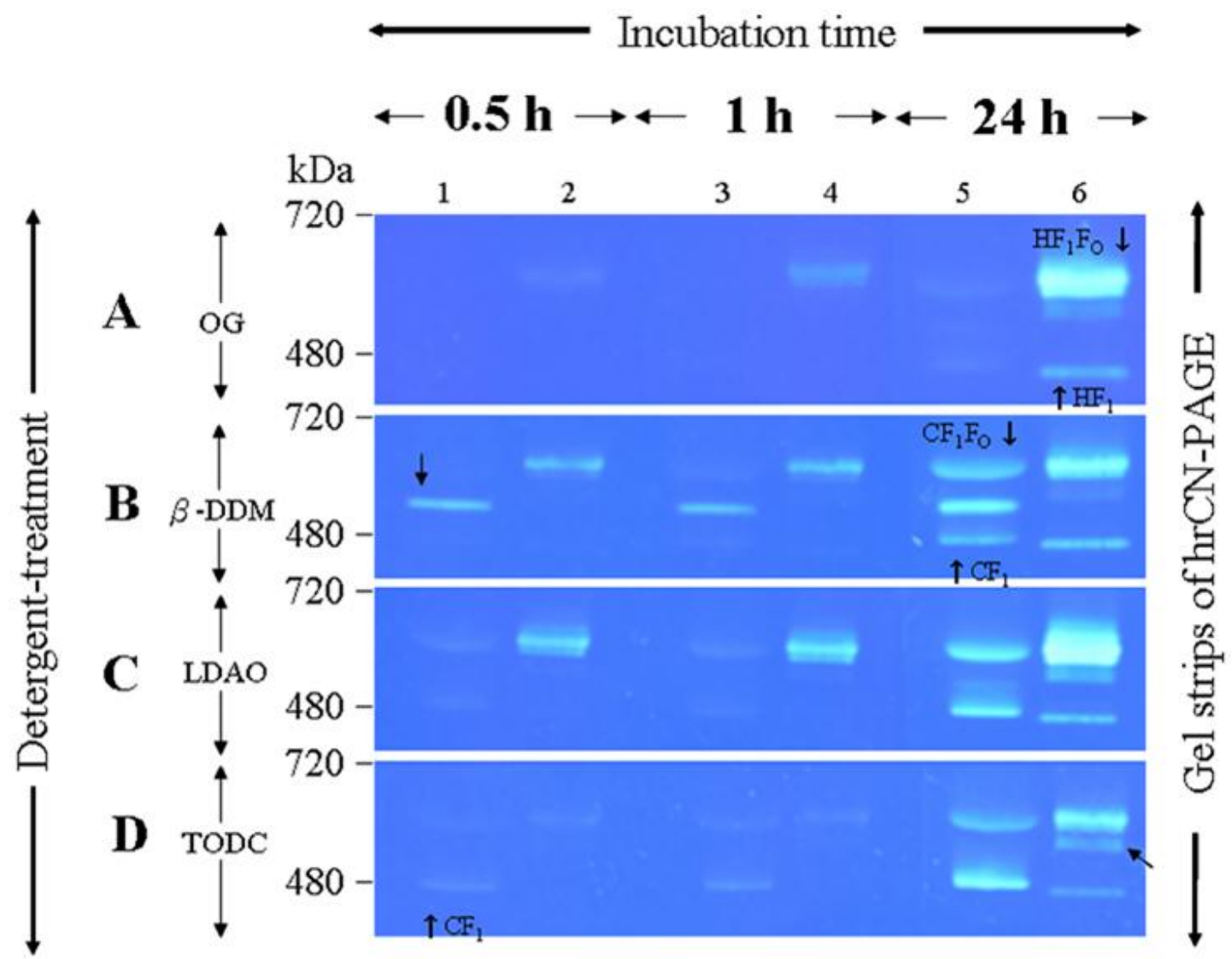

Figure. 7. In-gel ATPase hydrolysis activity of ATP synthase complexes isolated from spinach chloroplasts and $H$. modesticaldum.

The hrCN-PAGE gel strips, each containing $\mathrm{CF}_{1} \mathrm{~F}_{\mathrm{O}}$ and $\mathrm{HF}_{1} \mathrm{~F}_{\mathrm{O}}$, were incubated in buffers with different detergents to detect whether ATPase activity was dependent on the detergent. The gel strips were preincubated with buffer containing OG (A), $\beta$-DDM (B), LDAO (C) (Affymetrix/Anatrace, USA), or TDOC (D) (Sigma, USA). In the in-gel ATPase activity assay, ATP hydrolysis can be visualized as the white band comprising precipitated lead phosphate. Images of the in-gel assays were taken under a blue background after $0.5 \mathrm{~h}, 1 \mathrm{~h}$ and $24 \mathrm{~h}$ incubations, respectively.

Notably, under some detergent conditions, multiple subcomplex bands appear, as indicated by black arrows. These bands are observed, for example, for $\mathrm{CF}_{1} \mathrm{~F}_{\mathrm{O}}$ in $\beta$-DDM and LDAO and for $\mathrm{HF}_{1} \mathrm{~F}_{\mathrm{O}}$ in TODC. They might comprise $\mathrm{CF}_{1} \mathrm{~F}_{\mathrm{O}}$ and $\mathrm{HF}_{1} \mathrm{~F}_{\mathrm{O}}$ subcomplexes that have lost subunit a and/or $b$ of the $\mathrm{F}_{\mathrm{O}}$ domain during hrCN-PAGE electrophoresis. [lanes 1, 3, and 5, spinach chloroplast $\mathrm{CF}_{1} \mathrm{~F}_{\mathrm{O}}$ ATP synthase complex; lanes 2, 3, and 6, H. modesticaldum $\mathrm{HF}_{1} \mathrm{~F}_{\mathrm{O}}$ synthase complex]. 


\section{REFERENCE}

1. Tang, K.H., H. Yue, and R.E. Blankenship, Energy metabolism of Heliobacterium modesticaldum during phototrophic and chemotrophic growth. BMC Microbiol, 2010. 10: p. 150.

2. Sattley, W.M. and R.E. Blankenship, Insights into heliobacterial photosynthesis and physiology from the genome of Heliobacterium modesticaldum. Photosynthesis Research, 2010. 104(2-3): p. 113-122.

3. Turina, P., D. Samoray, and P. Graber, H+/ATP ratio of proton transport-coupled ATP synthesis and hydrolysis catalysed by CFOF1-liposomes. Embo Journal, 2003. 22(3): p. 418-426.

4. Bottcher, B., L. Schwarz, and P. Graber, Direct indication for the existence of a double stalk in CFOF1. J Mol Biol, 1998. 281(5): p. 757-62.

5. Pänke, O., and Rumberg, B., Energy and entropy balance of ATP synthesis. Biochimica et Biophysica Acta, 1997. 1322(2-3).

6. Peter Gräber, U.J.a.G.H.S., Kinetics of Proton-Transport-Coupled ATP Synthesis in Chloroplasts. Activation of the ATPase by an Artificially Generated $\triangle p H$ and $\triangle \psi$. Berichte der Bunsengesellschaft für physikalische Chemie, 1984. 88(7): p. 10.

7. Seelert, H., et al., Dye-ligand chromatographic purification of intact multisubunit membrane protein complexes: application to the chloroplast H+-FoF1-ATP synthase. Biochem J, 2000. 346 Pt 1: p. 41-4.

8. Poetsch, A., et al., Detergent effect on anion exchange perfusion chromatography and gel filtration of intact chloroplast $H(+)$-ATP synthase. Biochem Biophys Res Commun, 1999. 265(2): p. 520-4.

9. Evron, Y., E.A. Johnson, and R.E. McCarty, Regulation of proton flow and ATP synthesis in chloroplasts. J Bioenerg Biomembr, 2000. 32(5): p. 501-6. 
10. Hisabori, T., et al., Molecular devices of chloroplast F(1)-ATP synthase for the regulation. Biochim Biophys Acta, 2002. 1555(1-3): p. 140-6.

11. Hisabori, T., et al., Molecular evolution of the modulator of chloroplast ATP synthase: origin of the conformational change dependent regulation. FEBS Lett, 2003. 545(1): p. 71-5.

12. Junesch, U. and P. Graber, The rate of ATP-synthesis as a function of delta $p H$ and delta psi catalyzed by the active, reduced $H(+)$-ATPase from chloroplasts. FEBS Lett, 1991. 294(3): p. 275-8.

13. Kohzuma, K., et al., Light- and metabolism-related regulation of the chloroplast ATP synthase has distinct mechanisms and functions. J Biol Chem, 2013. 288(18): p. 13156-63.

14. Richter, M.L., Gamma-epsilon Interactions Regulate the Chloroplast ATP Synthase. Photosynth Res, 2004. 79(3): p. 319-29.

15. Ort, D.R., Oxborough, K., In Situ Regulation of Chloroplast Coupling Factor Activity. Annual Review of Plant Physiology and Plant Molecular Biology, 1992. 43: p. 23.

16. Suhai, T., et al., Highly sensitive detection of ATPase activity in native gels. Electrophoresis, 2009. 30(20): p. 3622-3625.

17. Richter, M.L., W.J. Patrie, and R.E. McCarty, Preparation of the epsilon subunit and epsilon subunit-deficient chloroplast coupling factor 1 in reconstitutively active forms. J Biol Chem, 1984. 259(12): p. 7371-3.

18. Gertz, M., et al., Interactions of rotor subunits in the chloroplast ATP synthase modulated by nucleotides and by Mg2+. Biochim Biophys Acta, 2007.

1774(5): p. 566-74.

19. Du, Z., et al., Assembled F1-(alpha beta) and Hybrid F1-alpha 3beta 3gamma -ATPases from Rhodospirillum rubrum alpha, wild type or mutant beta, and 
chloroplast gamma subunits. Demonstration of Mg2+versus Ca2+-induced differences in catalytic site structure and function. J Biol Chem, 2001. 276(15): p. $11517-23$.

20. Digel, J.G., et al., Differences between two tight ADP binding sites of the chloroplast coupling factor 1 and their effects on ATPase activity. J Biol Chem, 1996. 271(33): p. 19976-82.

21. Digel, J.G., K.E. Hightower, and R.E. McCarty, Subunit movement during catalysis by F1-F0-ATP synthases. J Bioenerg Biomembr, 1996. 28(5): p. 439-42.

22. Du, Z.Y. and P.D. Boyer, On the mechanism of sulfite activation of chloroplast thylakoid ATPase and the relation of ADP tightly bound at a catalytic site to the binding change mechanism. Biochemistry, 1990. 29(2): p. 402-7.

23. Ort, D.R. and K. Oxborough, Insitu Regulation of Chloroplast Coupling Factor Activity. Annual Review of Plant Physiology and Plant Molecular Biology, 1992. 43: p. 269-291.

24. Nalin, C.M. and R.E. McCarty, Role of a disulfide bond in the gamma subunit in activation of the ATPase of chloroplast coupling factor 1. J Biol Chem, 1984. 259(11): p. 7275-80.

25. Farron, F., Isolation and properties of a chloroplast coupling factor and heat-activated adenosine triphosphatase. Biochemistry, 1970. 9(19): p. 3823-8.

26. Sakurai, H., et al., Enhancement of Adenosine-Triphosphatase Activity of Purified Chloroplast Coupling Factor-I in an Aqueous Organic-Solvent. Journal of Biochemistry, 1981. 90(1): p. 95-102.

27. Anthon, G.E. and A.T. Jagendorf, Effect of Methanol on Spinach Thylakoid Atpase. Biochimica Et Biophysica Acta, 1983. 723(3): p. 358-365. 
28. McCarty, R.E., ATP synthase of chloroplast thylakoid membranes: a more in depth characterization of its ATPase activity. J Bioenerg Biomembr, 2005. 37(5): p. 289-97.

29. Pick, U. and S. Bassilian, Activation of magnesium ion specific adenosinetriphosphatase in chloroplast coupling factor 1 by octyl glucoside. Biochemistry, 1982. 21(24): p. 6144-52.

30. Yu, F. and R.E. McCarty, Detergent activation of the ATPase activity of chloroplast coupling factor 1. Arch Biochem Biophys, 1985. 238(1): p. 61-8.

31. Mesbah, N.M. and J. Wiegel, The Na(+)-translocating $F(1) F(0)$-ATPase from the halophilic, alkalithermophile Natranaerobius thermophilus. Biochim Biophys Acta, 2011. 1807(9): p. 1133-42.

32. Varco-Merth, B., et al., Crystallization of the c14-rotor of the chloroplast ATP synthase reveals that it contains pigments. Biochim Biophys Acta, 2008. 1777(7-8): p. 605-12.

33. Sarrou, I., et al., Purification of the photosynthetic reaction center from Heliobacterium modesticaldum. Photosynth Res, 2012. 111(3): p. 291-302.

34. Kimble LK, M.L., Woese CR, Madigan MT Heliobacterium modesticaldum, sp. nov., a thermophilic heliobacterium of hot springs and volcanic soils. . Arch Microbiol 1995. 163(4): p. 8.

35. Hartree, E.F., Determination of protein: a modification of the Lowry method that gives a linear photometric response. Anal Biochem, 1972. 48(2): p. 422-7.

36. Lowry, O.H., et al., Protein measurement with the Folin phenol reagent. J Biol Chem, 1951. 193(1): p. 265-75.

37. Schagger, H., Tricine-SDS-PAGE. Nat Protoc, 2006. 1(1): p. 16-22.

38. Wittig, I., M. Karas, and H. Schagger, High resolution clear native 
electrophoresis for in-gel functional assays and fluorescence studies of membrane protein complexes. Mol Cell Proteomics, 2007. 6(7): p. 1215-25.

39. Wittig, I., et al., Functional assays in high-resolution clear native gels to quantify mitochondrial complexes in human biopsies and cell lines. Electrophoresis, 2007. 28(21): p. 3811-20.

40. Merril, C.R., M.L. Dunau, and D. Goldman, A rapid sensitive silver stain for polypeptides in polyacrylamide gels. Anal Biochem, 1981. 110(1): p. 201-7.

41. Francis, R.T. and R.R. Becker, Specific Indication of Hemoproteins in Polyacrylamide Gels Using a Double-Staining Process. Analytical Biochemistry, 1984. 136(2): p. 509-514.

42. Lawrence, R.M., et al., Recombinant production and purification of the subunit c of chloroplast ATP synthase. Protein Expr Purif, 2011. 76(1): p. $15-24$.

43. Heinnickel, M. and J.H. Golbeck, Heliobacterial photosynthesis. Photosynthesis Research, 2007. 92(1): p. 35-53.

44. Chauvet, A., et al., Temporal and spectral characterization of the photosynthetic reaction center from Heliobacterium modesticaldum. Photosynth Res, 2013. 116(1): p. 1-9.

45. Heinnickel, M., et al., Identification of $F X$ in the heliobacterial reaction center as a [4Fe-4S] cluster with an $S=(3) /(2)$ ground spin state. Biochemistry, 2006. 45(21): p. 6756-6764.

46. Neerken, S. and J. Amesz, The antenna reaction center complex of heliobacteria: composition, energy conversion and electron transfer. Biochim Biophys Acta, 2001. 1507(1-3): p. 278-90.

47. Oh-oka, H., Type 1 reaction center of photosynthetic heliobacteria. Photochem Photobiol, 2007. 83(1): p. 177-86. 
48. Asao, M. and M.T. Madigan, Taxonomy, phylogeny, and ecology of the heliobacteria. Photosynth Res, 2010. 104(2-3): p. 103-11.

49. Sattley, W.M., et al., The genome of Heliobacterium modesticaldum, a phototrophic representative of the Firmicutes containing the simplest photosynthetic apparatus. J Bacteriol, 2008. 190(13): p. 4687-96.

50. Kashey, T.S., et al., Expression and characterization of cytochrome c553 from Heliobacterium modesticaldum. Photosynth Res, 2014. 120(3): p. 291-9.

51. Krause, F., et al., Active oligomeric ATP synthases in mammalian mitochondria. Biochem Biophys Res Commun, 2005. 329(2): p. 583-90.

52. Meyer, B., et al., Identification of two proteins associated with mammalian ATP synthase. Mol Cell Proteomics, 2007. 6(10): p. 1690-9.

53. Poetsch, A., et al., Dye removal, catalytic activity and $2 D$ crystallization of chloroplast H+-ATP synthase purified by blue native electrophoresis. Biochimica Et Biophysica Acta-Biomembranes, 2000. 1466(1-2): p. 339-349.

54. Schagger, H. and K. Pfeiffer, Supercomplexes in the respiratory chains of yeast and mammalian mitochondria. EMBO J, 2000. 19(8): p. 1777-83.

55. Wittig, I. and H. Schagger, Advantages and limitations of clear-native PAGE. Proteomics, 2005. 5(17): p. 4338-46.

56. Schafer, E., et al., Three-dimensional structure of the respiratory chain supercomplex IIIIIIIVI from bovine heart mitochondria. Biochemistry, 2007. 46(44): p. 12579-85.

57. Schafer, E., et al., Architecture of active mammalian respiratory chain supercomplexes. J Biol Chem, 2006. 281(22): p. 15370-5.

58. Seelert, H., N.A. Dencher, and D.J. Muller, Fourteen protomers compose the oligomer III of the proton-rotor in spinach chloroplast ATP synthase. J Mol 
Biol, 2003. 333(2): p. 337-44.

59. Fromme, P., Die ATP-synthase aus Chloroplast: Biochemische Untersuchungen zur Struktur and Kinetische Messungen zum Mechanismus des Enzyme. 1988, Technical University Berlin. p. 1-248.

60. Fromme, P., E.J. Boekema, and P. Graber, Isolation and Characterization of a Supramolecular Complex of Subunit-Iii of the Atp-Synthase from Chloroplasts. Zeitschrift Fur Naturforschung C-a Journal of Biosciences, 1987. 42(11-12): p. 1239-1245.

61. Neff, D. and N.A. Dencher, Purification of multisubunit membrane protein complexes: isolation of chloroplast FoF1-ATP synthase, CFo and CF1 by blue native electrophoresis. Biochem Biophys Res Commun, 1999. 259(3): p. 569-75.

62. Wittig, I. and H. Schagger, Native electrophoretic techniques to identify protein-protein interactions. Proteomics, 2009. 9(23): p. 5214-23.

63. Wittig, I. and H. Schagger, Features and applications of blue-native and clear-native electrophoresis. Proteomics, 2008. 8(19): p. 3974-90.

64. Wang, D. and P.R. Hiesinger, The vesicular ATPase: a missing link between acidification and exocytosis. J Cell Biol, 2013. 203(2): p. 171-3. 